INVESTIGACIÓN/RESEARCH

Recibido: 17/06/2015---Aceptado: 30/07/2015---Publicado: 15/09/2015

\title{
PUBLICIDAD Y FILOSOFÍA. PARECIDOS RAZONABLES
}

María Teresa Pellicer Jordá1: Universidad de Murcia. España.

maite.pellicer@um.es

Antonio Parra Pujante: Universidad de Murcia. España.

aparra@um.es

\section{RESUMEN}

La publicidad transmite una filosofía de vida propia, la cual supone una suma de algunos de los aspectos que conforman las diversas teorías filosóficas de todos los tiempos. La comparación de los principios entre unas y otras nos ofrecerán una visión conjunta, que nos permitirán comprender mejor el fenómeno publicitario. A lo largo de este artículo, analizaremos los principios más importantes de las principales teorías éticas y encontraremos parecidos razonables.

\section{PALABRAS CLAVE}

Publicidad-Ética-Filosofía-Normas- Moral-Sociedad-Valores-Anuncios-Educación

\section{ADVERTISING AND PHILOSOPHY. REASONABLE RESEMBLANCES}

\begin{abstract}
Advertising transmits a philosophy having its own life, which entails the sum of some of the aspects that shape the diverse philosophical theories of all times. The comparison of the principles between some and other philosophies will offer a joint vision, which will allow us better understanding of the advertising phenomenon.

\footnotetext{
${ }^{1}$ María Teresa Pellicer Jordá: La autora es profesora en la Facultad de Comunicación y Documentación de la Universidad de Murcia. Es autora de dos libros, titulados 'Ética y estrategias publicitarias' y 'La publicidad como industria cultural', así como de varios artículos en revistas especializadas en Comunicación.

maite.pellicer@um.es
} 
Along this article, we will analyze the most important principles of the main ethical theories and find reasonable resemblances.

\section{KEY WORDS}

Advertising-Ethics-Philosophy-Standards-Morality-Society-Values-AdvertsEducation

\section{INTRODUCCIÓN}

Como explica Enrique Bonete:

"Durante siglos, el pensamiento filosófico en nuestra civilización occidental ha ofrecido principios éticos, a veces incompatibles entre sí y, por ello, en continua discusión, para justificar o impulsar determinadas formas de vida, exigencias morales o ideales sociopolíticos, desde aquellos diálogos platónicos- tan lejanos en el tiempo como vigentes en su temática ética- hasta los recientes y polémicos filósofos postmodernos (1999:21-22)”.

\section{OBJETIVOS Y METODOLOGÍA}

Lo cierto es que la publicidad propugna, también, determinados valores, formas de vida, etc, lo que conforma una filosofía propia de la publicidad. A lo largo de este artículo queremos comparar las principales teorías filosóficas de todos los tiempos con la filosofía publicitaria, lo que nos permitirá encontrar parecidos razonables. Con este objetivo, vamos a analizar los principales movimientos filosóficos haciendo especial hincapié en los siguientes puntos:

- Concepto y defensa de la ética y de la moral en todos los ámbitos de la vida. De este modo, conoceremos qué importancia se le da a estos aspectos y cómo se definen según las diversas teorías.

- La idea de felicidad que se plasma en cada una de ellas, por estar ésta ligada de forma directa a la moral y ser el mensaje principal que se transmite a través de la publicidad. Todos los anuncios, al margen del producto o servicio que vendan, transmiten en último término la idea de la felicidad que producirá al consumidor disponer de ese producto o servicio. De ahí que queramos conocer qué concepto de felicidad se tiene en cada una de estas teorías y si este concepto está presente en las mismas.

- El modo de vivir y de obrar que proponen, ya que la publicidad también trabaja en este ámbito al sugerir modos de comportamiento.

\section{DISCUSIÓN}

\subsection{La publicidad, el sofista del siglo XXI}


El primer movimiento filosófico que vamos a analizar va a ser el sofismo, una corriente cuyos postulados nos recuerdan a la época actual en lo que a publicidad se refiere, como podrán comprobar en las siguientes líneas.

El movimiento sofístico aparece en Grecia en el siglo V. Se caracteriza externamente por unas cuantas notas: son profesores ambulantes, que van de ciudad en ciudad, enseñando a los jóvenes y enseñan por dinero, mediante una retribución, caso nuevo en Grecia y que sorprendió bastante a la sociedad de la época.

Pero ¿en qué consistía esa enseñanza? Estos filósofos- que no eran considerados como tales por Aristóteles y Platón-, enseñaban "el arte de hablar persuasivamente en público, mediante la práctica de la argumentación y el ejercicio continuado en debates sobre cuestiones éticas o políticas (Melero Mellido, 1996:11)", algo fundamental en la Átenas del tiempo. Idea a resaltar ésta, ya que la persuasión es la herramienta fundamental de la publicidad. En tal caso y haciendo una analogía, podríamos decir que los sofistas enseñaban a hacer la publicidad de ese tiempo, una publicidad eminentemente oral. Por tanto, los sofistas enseñaban a convencer, utilizando la persuasión, del mismo modo que hoy en día hace la publicidad. Es más, los cursos que impartían los sofistas (Melero Mellido, 1996:15) eran objeto de una publicidad previa, una epangelía, cuya formulación podía ser muy general. Por ejemplo, Protágoras prometía el perfeccionamiento moral o la excelencia política. Es decir, los sofistas ya sabían de promesas publicitarias y de eslóganes, algo que hace si cabe más valioso para nosotros este movimiento filosófico.

Volviendo a la idea anterior de la retórica, la enseñanza de los sofistas, debemos destacar la siguiente idea que postulan los mismos: se trata de decir las cosas de modo que convenzan, de decir bien. No importa la verdad. Quizá por eso es por lo que los sofistas no eran considerados filósofos, como apuntábamos en líneas anteriores, por Aristóteles o Platón, que defendían la verdad y el bien pensar (Marías, 1941:69). Aquí también vemos una analogía con la publicidad. Lo importante es vender, no la verdad. Las cosas hay que decirlas, igual que propugnaban los sofistas, de modo de convenzan. Eso es lo importante en publicidad, vender, aspecto que seguiremos matizando a lo largo de esta investigación.

De los párrafos anteriores, podemos extraer las dos críticas fundamentales que se hacía a los sofistas: "Los sofistas no eran pensadores serios, sino una suerte de charlatanes, sin ningún conocimiento serio de materia filosófica alguna; y eran profundamente inmorales (Marías, 1941:53)". Idea ratificada por Aristóteles, cuando decía que "la sofística es una sabiduría aparente y no real; y el sofista un negociante de sabiduría aparente y no real (Marías, 1941:75).

Permítannos resaltar otro aspecto más dentro del sofismo: la presencia del dinero. Como hemos visto, los sofistas enseñaban el arte de la retórica a cambio de dinero, algo poco usual y criticado en la Grecia de entonces. En este punto también encontramos similitud con la publicidad, en donde la economía y, por ende el dinero, son fundamentales.

Haciendo una analogía entre sofismo y publicidad, podríamos decir que los sofistas enseñaban las técnicas persuasivas, la retórica, a cambio de dinero. La aplicación de estos conocimientos quedaba a merced del alumno, que determinaría dónde, cuándo y cómo aplicar este saber convencer. Podríamos continuar esta analogía afirmando 
que la publicidad es un alumno del sofismo, que aprendió muy bien la técnica y la decidió aplicar a la venta de productos y servicios, lo que permitía ganar dinero.

Pero vayamos más allá, con la descripción que hace de los sofistas Platón:

En primer lugar- el sofista- resultó ser un cazador de sueldo de jóvenes pudientes (...) En segundo lugar, alguien que comercia con las ciencias del alma (...) En tercer lugar, no se ha revelado como un detallista de las mismas materias (...) En cuarto lugar, alguien que nos ofrece en venta los productos de su invención para la enseñanza de las ciencias (...) Y en quinto lugar, una especie de atleta de la competición de discursos, que se ha apropiado del arte de la erística (...) El sexto punto es ciertamente discutible; sin embargo acordamos concederle que es un purificador de las opiniones que suponen un obstáculo para los conocimientos del alma (Melero Mellido, 1996:73-74).

En esta descripción también podemos encontrar referencias a la publicidad actual. Nosotros hacemos la siguiente interpretación, de acuerdo a la cita de Platón:

- La publicidad es una cazadora de sueldo de jóvenes pudientes y no pudientes, ya que fomenta el consumo, algo que tiene diversas connotaciones como ya veremos a lo largo de esta investigación.

- La publicidad comercia con las ciencias del alma, ya que vende valores, estereotipos, sueños, deseos, bienestar emocional, etc.

- La publicidad es una especie de atleta de la competición de discursos, sobre todo debido a la gran competencia publicitaria que existe y a la necesidad de convencer más y más rápido que el competidor.

- La publicidad es un purificador de las opiniones, ya que, como veremos más adelante, se encarga de crear modelos de conducta y hábitos sociales.

Hemos visto que el sofismo y la publicidad tienen en común muchos más elementos que de los que pudiéramos pensar inicialmente, lo que nos lleva a afirmar que el sofismo en Grecia es la publicidad de hoy en día. Coinciden en postulados, objetivos y modos de obrar. La publicidad es el sofista del siglo XXI.

\subsection{Sócrates y la necesidad de la moral}

Como decíamos anteriormente, el hombre se había convertido en el protagonista de la filosofía griega. Si los sofistas se centraban en el modo de hacer del hombre, en la parte externa, Sócrates comienza una etapa reflexiva, donde lo importante es conocerse a uno mismo. Esta postura es la que llevaría al filósofo a decir que "la vida sin examen no es digna de ser vivida" (Robinson Chris, 2005:32), una vida en la que los dioses y éstos, a través de la naturaleza, ofrecen al hombre lo importante de la vida, algo que cobra especial relevancia en sus teorías.

Como vemos, la ética socrática insta a conocerse a uno mismo, pero también tiene tintes morales, algo que no veíamos en la corriente sofística estudiada anteriormente. Esto es lo que nos interesa de sus postulados, la introducción del concepto de moral. Para Sócrates el conocimiento moral se puede alcanzar mediante el debate y la discusión, aunque matiza que "la moralidad no es un género de conocimiento que pueda realmente enseñarse (2005:33)", añade Dave Chris-Robinson. 
Lo cierto e importante, como decíamos, es que Sócrates reflexiona sobre la moral y sobre su necesidad en la vida. La moral se convierte, de este modo, en algo fundamental para conseguir la felicidad, otro elemento importante a destacar dentro de la filosofía socrática. El propio filósofo lo explica de la siguiente forma:

Hasta los placeres mismos, que es el único fin al que parece conducir a los hombres a la incontinencia, ésta ni puede a ellos conducirlos, mientras que el dominio de sí mismo es lo que más de todo hace gozar de los placeres. (...) Pero sólo a los que tienen dominio de sí mismos es dado mirar las cosas que más importan y, con palabras y hechos discerniéndolas en sus clases, elegir las buenas y apartarse de las malas. Con que así era como decía que llegaban a ser los hombres los mejores y los más felices y los más capaces para discurrir y dialogar (Jenofonte, 1967:169).

Vemos como la moral se convierte, según Sócrates, en la causa y razón de la felicidad, con la moral se hace a los mejores hombres, a los hombres que mejor pueden gobernar. Pero, como decíamos, no sólo es importante esta idea de moral, que el filósofo introduce en todos los ámbitos de la vida y que da lugar a los mejores profesionales, sino que también es relevante la concepción de la felicidad como resultado de esa moral. Es decir, un comportamiento ético y moral hace feliz a los hombres, según Sócrates. Si tenemos en cuenta que nuestro trabajo versa sobre la ética o la falta de ética, en muchos casos, de la publicidad, podríamos concluir, siempre siguiendo los postulados socráticos, en que una publicidad ética haría más feliz a los hombres, cuestión sobre la que seguiremos reflexionando a lo largo de la investigación.

\subsection{Platón. La felicidad como bien supremo.}

La filosofía de Platón es muy amplia y, por ello, nosotros nos vamos a centrar en aquellos aspectos que nos son de utilidad para nuestra investigación. Éstos serían: el concepto del bien, la felicidad y la introducción del concepto de sociedad como algo importante para el hombre, según Platón. Estos tres aspectos son los que consideramos más relevantes pata nuestro objeto de estudio y, por ello, vamos a analizarlos convenientemente.

Comenzamos hablando del concepto del bien que tiene Platón, un filósofo cuyo objetivo central fue siempre buscar el ser de las cosas. Para Platón, el verdadero bien del hombre se alcanza a través de la virtud, la cual se relaciona con el conocimiento. Pero ¿cómo se adquiere ese conocimiento? El filósofo lo explica a través de uno de sus mitos, el mito del Fedro, un mito en el que el alma se compara con un carro tirado por dos caballos, uno dócil y de buena raza y el otro díscolo (los instintos sensuales y las pasiones) dirigido por una auriga (la razón). Este carro circula por el mundo de las ideas, pero las dificultades para guiar el tiro de los dos caballos hacen que el alma caiga y, por tanto, se encarne en cuerpo, un cuerpo que será animal o humano según el alma haya visto o no las ideas. De esta forma, el origen del hombre es "una caída de un alma, de procedencia celeste que ha contemplado las ideas, pero que al encarnarse en hombre no las recuerda (Marías, 1941:77)". Platón lo explica de la siguiente forma: 
Digamos, pues que (el alma) se parece a las fuerzas reunidas de una alada yunta y de un conductor; los corceles y conductores de las almas divinas son todos excelentes y de buena raza; pero en los demás seres, su naturaleza participa del bien y del mal. Así es que en nosotros el conductor dirige dos corceles, uno excelente y de excelente raza, otro muy diferente del primero y también de diferente origen. Ahora bien, el semejante tronco tiene forzosamente que ser penoso y difícil de guiar. (...) La virtud de las alas consiste en remontar lo que es pesado a las más elevadas regiones donde habita la raza de los dioses, y participar de lo que es divino más que todas las cosas corporales. Ahora bien, lo divino es lo bello, bueno y sabio y todo lo que posee análogas cualidades; $\mathrm{y}$ es también lo que sostiene y fortifica las alas del espíritu; todas las demás cualidades contrarias, como la maldad o la fealdad, las debilitan y las hacen perder (2003:164).

Con este mito, Platón vuelve a recordar la idea, al igual que lo haría Sócrates, que conocer no es ver lo que está fuera sino lo que está dentro de nosotros. Ése es el método del conocimiento, que nos hará llegar a la virtud y, por tanto al bien.

Otro de los mitos que nos resultan de interés para nuestro objeto de estudio es el famoso mito de la Caverna, un mito en el que se representa simbólicamente la situación del hombre con la filosofía y la estructura de la realidad. De este mito, al margen de la reflexión sobre los postulados de Platón, podemos desgranar una idea importante: lo difícil que resulta ir a contracorriente. Éste es un pensamiento muy actual que también se puede reflejar en el mundo publicitario y en sus efectos en la sociedad. De ahí la razón de citar este texto. Siguiendo con nuestra reflexión, podemos decir que la publicidad de hoy en día nos impone un mundo determinado, unos hábitos de vida garantes de éxito y, en definitiva, unos modelos de conducta. Al igual que le ocurre al encadenado que sabe que la realidad no es como sus compañeros piensan y que teme por su vida si se lo cuenta a ellos, podríamos decir que hoy en día, según los patrones establecidos por la publicidad, es difícil ir a contracorriente sin resultar perjudicado socialmente por la hazaña. Es una reflexión interesante, que se puede trasladar a cualquier ámbito, y que nosotros aplicamos al mundo de la publicidad. ¿Qué le ocurriría a alguien que quisiera desmarcarse de los modelos de conducta socialmente aceptados, e implantados en gran parte por la publicidad? ¿Sería marginado por sus semejantes? O si no ¿por qué todos queremos llevar ese modelo de vida, a pesar de que en ocasiones no tengamos los recursos económicos para ello? ¿Por qué todos debemos llevar el móvil de última generación o cualquiera aspira a tener un Mercedes? ¿No será quizá porque esos estilos de vida, que son, repetimos, los que sugiere la publicidad, son los que nos aseguran el éxito social y la no marginación?

Atención a la siguiente cita de Platón: "Si un tipo de carácter es más fuerte que los otros, por decirlo así, ¿no crees que arrastrará a los demás consigo? (Blackburn, 2007:131)". Sí, sólo de este modo pueden surgir los sistemas políticos. Esta idea del autor ratifica el planteamiento que hemos expuesto en el párrafo anterior. La cuestión es que ese carácter más fuerte, en este caso la publicidad, es más fuerte por su capacidad de difusión y por los valores que transmite, valores y deseos que forman parte de las aspiraciones de todos. Quizá por eso es por lo que la publicidad es más fuerte, 
porque nos hace creer que conseguiremos, en definitiva, la felicidad tan ansiada, a través del éxito social y todo lo que nos promete.

Otra cita interesante del filósofo es la siguiente: "Fíjate en lo que voy a decir: ¿cuál de estas dos cosas se propone siempre y en todos los casos la pintura? ¿Representa los hechos del mundo real o las apariencias? ¿Es la apariencia lo que representa o la verdad? (Blackburn, 2007:150)". Consideramos esta cita interesante porque nos remite a algunas de las críticas a las que se ve sometida la publicidad, si vende cosas reales o apariencias. Seguiremos reflexionando a lo largo de estas ideas, pero vamos a continuar estudiando la filosofía de Platón en este mito.

Como explica Julián Marías, este mito simboliza:

A la vez la estructura ontológica de lo real y la significación de la filosofía (1941:79), introduciendo una unidad fundamental entre estos dos mundos. Pero no debemos olvidar que el viaje del hombre del mito es de ida y vuelta: el encadenado, una vez que ha contemplado el mundo de la luz y la libertad, vuelve a la caverna. Es decir, "va a explicar la realidad desde las cosas de las sombras, desde las ideas la realidad sensible (1941:80). Platón, considera, de esta forma, que "la filosofía es el proceso intelectual que permite huir del mundo de las apariencias para introducirse en el de las ideas (Roura, 2001:26)

Una vez estudiado el concepto de bien para Platón, considerada la idea suprema, vamos a pasar a estudiar su concepción de felicidad, relacionada directamente con la idea anterior. Para Platón, la felicidad es posible cuando el hombre es capaz de llegar hasta las ideas, es decir, hasta la esencia de las cosas. Hasta esa esencia se llega a través de la virtud, antes tratada. Vemos como el concepto de felicidad de Platón es muy profundo y tiene que ver con el interior del hombre y no con el exterior, como nos hace creer la publicidad.

La tercera de las ideas de Platón que nos gustaría resaltar es la relacionada con la sociedad. El filósofo ve a la sociedad como algo natural del hombre, es decir, el hombre necesita vivir en sociedad porque no es autosuficiente, sino que necesita de los demás.

Como explica el filósofo (1989:59), la ciudad se puede considerar también, a semejanza del alma, como un todo compuesto de tres partes, que corresponden a las psíquicas. Estas partes son las tres grandes clases sociales que reconoce: el pueblo, compuesto de comerciantes, industriales y agricultores; los vigilantes y los filósofos. Cada uno de estos colectivos tiene una virtud: la de las clases productora la templanza, la de los vigilantes o guerreros, la fuerza, y la de los filósofos, la sabiduría. Una idea importante dentro del concepto de sociedad que plantea Platón es que la educación es la que determinará la clase a que se ha de pertenecer. Como vemos, el principio de especialización es la base de la moral en el Estado de Platón. Como él mismo afirma, "no hay pues nada más pernicioso para la ciudad que el entrometimiento mutuo de estas tres clases o el cambio de papeles entre ellas y nada podría calificarse con más razón de crimen (Blackburn, 2007:87)".

Dentro de este concepto de sociedad, el filósofo introduce otra idea, la de justicia, que consistiría en el equilibrio y buena relación de los individuos entre sí y con el Estado, y de las diferentes clases entre sí y con la comunidad social. 
Respecto a esta tercera idea de Platón debemos hacer varios comentarios. El primero de ellos hace referencia a esa diferenciación de clases sociales y a la idea de que cuando se entremezclan aparecen los problemas y desaparece el equilibrio de la sociedad. En este sentido, debemos resaltar que la publicidad intenta homogeneizar a la sociedad, es decir, que no existan clases sociales o que todos aspiremos a una clase social a la que no pertenecemos, obviamente una clase social superior a la nuestra. De ahí vienen muchas de las frustraciones de las personas, que ven como el no poder acceder a determinados bienes, les condena a una clase social inferior. Ésta es una de las ideas recurrentes en publicidad, que siempre nos incita a ser más.

Una segunda reflexión es que si en la sociedad de Platón, la educación determinaba la clase social a la que se pertenece, en la sociedad actual el factor determinante es el dinero y lo que puedas adquirir con ese dinero.

\subsection{Aristóteles y su búsqueda de la felicidad}

La filosofía de Aristóteles se centra fundamentalmente en la búsqueda de la felicidad, de ahí la importancia de sus teorías para nosotros, ya que, como explicábamos anteriormente, la felicidad es el sentimiento o sueño último que vende la publicidad. De ahí la importancia de estudiar las distintas concepciones que han existido sobre la misma a lo largo de los tiempos. Pero la cuestión de la felicidad no va a ser la única que nos interese del filósofo, sino que hay otras dos que también vamos a estudiar: la introducción del concepto de fantasía y la concepción del comercio que tenía Aristóteles.

Comenzamos hablando de la felicidad, concepto sobre el que gira toda la filosofía del autor griego. Para Aristóteles, el bien es el fin último de las cosas y, por tanto, de las acciones humanas y coloca a la felicidad como el bien supremo, es decir, como el mayor bien que puede tener el hombre.

La siguiente cuestión en este sentido es ¿qué es la felicidad para Aristóteles? "La felicidad es la plenitud de la realización activa del hombre, en lo que tiene de propiamente humano (Marías, 1941:103)". Una definición que se adapta a cualquier tiempo porque es cierto que la felicidad es una consecuencia directa de la realización completa del hombre. Y añade que "todos convienen generalmente en que la felicidad es el mayor y más precioso de los bienes a los que puede aspirar el hombre (Aristóteles, 2000:22)".

Ahora bien, ¿cómo alcanzar esa felicidad? Según afirma el propio Aristóteles los tres bienes de felicidad más grandes para el hombre son "la virtud, la prudencia y el placer (2003:15)" o lo que es lo mismo los bienes exteriores, los bienes del alma y los bienes del cuerpo. Para ser feliz, según el filósofo, hay que lograr la armonía entre estos tres bienes y resume esta concepción en la siguiente frase: "Lo justo es lo más bello, la salud lo mejor y obtener lo que se ama es lo más dulce para el corazón (1992:82)". Vemos como Aristóteles concibe la felicidad como la armonía entre esos tres bienes, pero recalca la necesidad del hombre de luchar por conseguirlos. De esta manera, apunta que la felicidad no es un efecto del azar. Es a la vez un don de los dioses y el resultado de nuestros esfuerzos. Sólo en vista de la felicidad hacemos todo lo que hacemos y añade otra frase interesante para nuestro estudio: "Uno se hace virtuoso ejecutando actos de virtud (1992:105)". 
De acuerdo a todo lo expuesto, para Aristóteles la felicidad se consigue con el esfuerzo del hombre por conseguir esos tres bienes tan preciados, lo que implica una lucha del hombre, lucha que le llevará a conseguir su objetivo. Lo curioso es que esta concepción de felicidad y de cómo conseguirla que tiene Aristóteles y que nos parece bastante razonable, es diferente a la que transmite la publicidad: una felicidad conseguida a través de lo material, sin esfuerzo o con el esfuerzo de la compra. Así se es feliz, según intentan transmitir los anuncios publicitarios.

El segundo aspecto que vamos a tratar dentro de la filosofía Aristotélica es el de la fantasía. El filósofo introduce en su teoría el concepto de la imaginación, interesante para nuestro tema de estudio porque la publicidad juega mucho con esa fantasía y con nuestras fantasías, las fantasías de tener éxito, ser guapos, jóvenes, etc. A través de un anuncio, la publicidad incita a nuestra fantasía y a nuestra capacidad de imaginar. En este sentido, Aristóteles explica que "frente al puro, propio de la percepción- tenemos el de la fantasía (...), que es una cosa débil. La imaginación tiene un carácter de debilidad respecto de la fortaleza y de la claridad propia e impositiva de las cosas reales (Zubiri, 2005:25)". Xavier Zubiri añade que "la filosofía- por lo menos inspirada en Aristóteles- asignaba un tercer carácter a la fantasía, que es la libre movilidad" (2005:36). Esa libre movilidad es la que hace, por ejemplo, que los compradores de una marca importante, como por ejemplo, Nike, se sientan mejor vistos socialmente y se sientan, en definitiva, en un grupo social determinado, a pesar de que no sea así, como veremos más adelante.

Aristóteles fue más allá en su filosofía, haciendo referencia a la ética comercial, tercer aspecto que queremos destacar, ya que la publicidad tiene una más que estrecha relación con el comercio, ya que trata de anunciar productos de diversos comercios, hoy llamados marcas, para vender. Sergio Ramos resume la concepción del comercio que no sólo tenía Aristóteles, sino también corrientes posteriores y lo hace de esta forma:

Él -Aristóteles- distinguió entre el oikonomíkos o comercio doméstico, que aprobaba y consideraba esencial para el funcionamiento de cualquier sociedad, y el chrematisike o el comercio para el lucro. A este último, que nosotros podemos identificar con la publicidad claramente, lo juzgaba como desprovisto de virtud y a quienes se dedicaban a estas prácticas, y particularmente a prestar dinero, incluso los consideraba como parásitos. Los grandes pensadores de la Edad Media, teólogos comprometidos con su iglesia, también condenaron la avaricia y codicia de los comerciantes. A esa época se remonta la idea de que el comercio y los negocios son amorales. Esta forma de pensar no cambió ni cuando los hombres de negocios separaron la ética de la economía, a finales del siglo XVIII por influencia de los economistas clásicos, quienes justificaron la economía con un enfoque utilitarista y, para efectos de análisis, la consideraron un conjunto de actividades lucrativas ajenas a consideraciones éticas. De esta época es la noción de que la ética es una cosa y los negocios otra, es decir, como se dice popularmente hoy en día, los negocios son los negocios (2008:9).

\subsection{Los Cínicos. La independencia del hombre.}


Hemos visto hasta el momento varias concepciones de felicidad, aspecto que repetimos, nos importa especialmente ya que es uno de los reclamos publicitarios más importantes, por no decir el principal. Ahora vamos a conocer la concepción de la felicidad que tenían los cínicos, una concepción distinta a las estudiadas hasta el momento, pero que introduce un elemento importante: la independencia del hombre, otro aspecto también relacionado en parte con la publicidad actual.

Con los cínicos se cambia el paradigma dentro de la filosofía estudiada hasta el momento. Como explica Julián Marías:

La doctrina cínica, si existe, es bien escasa; es más bien la renuncia de toda teoría, el desdén por la verdad. Sólo importa lo que sirve para vivir, se entiende, al modo cínico. El bien del hombre consiste simplemente en vivir en sociedad consigo mismo. (...) El placer de los sentidos y el amor son lo peor, lo que más hay que rehuir. El trabajo, el ejercicio, el comportamiento ascético, es lo único deseable para el hombre según los cínicos e indiferente la familia y la patria. Se sienten ciudadanos del mundo. Es la primera aparición importante del cosmopolitismo, que va a gravitar tan fuertemente en el mundo helenístico y romano (1941:110).

De esta manera, vemos como los cínicos hablaban de la independencia del hombre y de la renuncia a la verdad- aspecto este último que compartían, en parte, los sofistas. La publicidad se centra más en el éxito social, es cierto, pero siempre desde la independencia del hombre. Ahora bien, para los cínicos, no tienen cabida los placeres y las riquezas, algo antagónico totalmente con la sociedad actual y con la concepción de la publicidad.

\subsection{Los Epicureos. El placer como verdadero bien.}

Con los epicureos volvemos a ver otro cambio en el paradigma filosófico. La filosofía epicúrea es materialista, a diferencia de las corrientes estudiadas hasta el momento. Todo es corporal, formado por la agregación de átomos diversos. Para ellos, el universo es puro mecanismo, sin finalidad de intervención alguna de los dioses en él.

Ese apego a lo material, como decimos otro aspecto propugnado por la publicidad actual, no es el único aspecto que nos interesa de los epicureos, sino que hay otro más que vamos a analizar: la concepción positiva del placer como el verdadero bien del hombre. El propio Epicuro lo explica de la siguiente forma:

Decimos que el placer es punto de partida y fin de una vida bienaventurada. Porque reconocemos al placer como bien primario y connatural. Iniciamos todo acto de aceptación y de rechazo partiendo de él, y es al placer adonde volvemos al utilizar nuestra experiencia del placer como criterio de toda buena cosa. (...)Toda criatura viviente, desde el momento de nacer, se deleita en el placer, así como resiste al dolor provocado por causas naturales independientemente de la razón (Long, 1984:69).

Es interesante esta concepción tan positiva del placer de lo material, ya que hasta el momento los placeres intelectuales o inmateriales eran los únicos admitidos por los 
filósofos para conseguir la tan ansiada por todos felicidad. El placer se convierte, de esta forma, en lo que identifica las cosas que son buenas o malas para el hombre, según los epicureos. Pero debemos hacer una salvedad. Epicuro exige muy determinadas condiciones al placer:

Ha de ser puro, sin mezcla de dolor ni de desagrado; ha de ser duradero y estable; ha de dejar al hombre, por último, dueño de sí, libre, imperturbable (...) Con lo cual se eliminan totalmente los placeres sensuales para dejar paso a otros más sutiles y espirituales y, ante todo, a la amistad y a los goces del trato. Las pasiones violentas quedan excluidas de la ética epicúrea. El ideal del sabio es, pues, el del hombre sereno, moderado en todo, regido por la templanza, sin inquietudes (...) Ni la adversidad, ni el dolor físico, ni la muerte alteran al epicúreo (Long, 1984:69).

Volvemos a ver en este punto identificaciones con la publicidad actual ya que el éxito en las relaciones sociales es otro de los valores fundamentales que vende la publicidad. De hecho, aún cuando parece vendernos la idea de sensualidad, lo hace con el objetivo de atraer a otras personas, con lo que el éxito social vuelve a ser el valor transmitido.

Respecto a la prudencia, Epicuro afirma lo siguiente:

La prudencia es el punto de partida de las fuentes del placer y el mayor bien. Por tanto, la prudencia es algo todavía más valioso que la filosofía. De la prudencia nacen todas las otras virtudes y ella enseña que no es posible vivir placenteramente sin vivir prudente, noble y justamente sin vivir placenteramente. Pues las virtudes se hallan de modo natural ligadas al vivir placentero y el vivir placentero es inseparable de aquéllas (Long, 1984:75).

De esta forma, vemos como para los epicureos la felicidad es alcanzable fácilmente. Sólo es necesario buscar los placeres y evitar el dolor. ¿No nos recuerda esta concepción al modelo de sociedad actual? Consideramos que el parecido en cuanto a la filosofía de vida de los epicureos y la sociedad moderna es bastante grande, a pesar de los siglos que los separan. Esta concepción, como veremos más adelante, ha sido creada en gran parte por la publicidad, que propugna el consumo y la compra o adquisición de productos materiales como los satisfactores del placer y, por ende, los causantes de la felicidad.

\subsection{Kant. El deber por el deber mismo.}

La siguiente teoría filosófica que vamos a estudiar es la de Kant. De él nos interesan tres cuestiones fundamentales, a nuestro juicio, que plasma en sus teorías: la concepción del hombre, la importancia del deber y de la moralidad y su concepto de felicidad.

Según Roura "cuando hizo su aparición Kant, el racionalismo se había convertido en un dogmatismo, y el empirismo por su parte, hablaba de la experiencia propia como la única posibilidad de conocimiento y había invalidado absolutamente la razón, conduciendo al escepticismo (2001:27)". 
Comenzamos estudiando la concepción sobre el hombre que tiene Kant. Su teoría gira en torno a la pregunta ¿qué es el hombre?, pregunta que, a su vez, engloba otras tres: ¿qué puedo saber?, ¿qué debo hacer? y ¿qué cabe esperar? Es decir, el autor, para saber qué es el hombre, debe conocer primero sus posibilidades de conocimiento, la forma correcta de actuar y el objetivo o fines que se conseguirán con esa forma de actuar, ya que para Kant el modo de obrar es fundamental en la consecución de cualquier objetivo.

La siguiente cuestión que se deriva del planteamiento anterior es ¿cómo debemos actuar? Según el filósofo la respuesta es clara: con moralidad y con responsabilidad.

Respecto a la primera cuestión, la de la moralidad, la teoría de Kant se basa en el deber por el deber mismo. Es, como explica Roura, "la conducta humana no debe estar condicionada por ningún bien o fin que se quiera obtener $\mathrm{y}$, por tanto, no debe basarse en una serie de máximas morales que garanticen la obtención de ese bien. Debe basarse en el deber por el deber mismo (2001:27). En tal caso, la felicidad sería un fin que, en principio, no debe ser buscado por el hombre, sino que es una consecuencia de esas actuaciones basadas en la moralidad. Es decir, para Kant, las cosas deben hacerse porque deben ser así, al margen de los objetivos que uno persiga. Ésta es una idea clave porque resalta la importancia de actuar siempre según la moral, dejando de lado las pretensiones de cada uno y esta idea debería ser aplicada a la publicidad, que siempre debería cumplir con las normas éticas y morales, al margen de su finalidad.

De esta manera, podemos resumir el pensamiento de Kant con algunas de sus máximas:

- Aspiración a la virtud: el hombre debe hacer las cosas de la mejor forma posible.

- El contenido moral se convierte en la tarea moral de la vida de toda persona.

- La fuerza obligatoria del deber

- Obra sólo según una máxima tal que puedas querer al mismo tiempo que se torne ley universal (Kant, 1967:78)

- El hombre es un fin en sí mismo, tiene dignidad

- "Obra de tal modo que uses la humanidad, tanto en tu persona como en la persona de cualquier otro, siempre como un fin al mismo tiempo y nunca solamente como un medio (Kant, 1967:41)".

Este último aspecto, la fuerza obligatoria del deber sería lo que Kant denominó imperativo categórico. Según el autor, los deberes morales son incondicionales y universalizables. Añade que "las leyes morales- el imperativo categórico- proceden de la legislación de la propia voluntad (1967:225).

Kant distingue dos tipos de imperativo: uno el categórico, del que ya hemos hablado, y el imperativo hipotético. Él los explica de la siguiente manera:

Todos los imperativos mandan, ya hipotética, ya categóricamente. Aquéllos representan la necesidad práctica de una acción posible, como medio de conseguir otra cosa que se quiere. El imperativo categórico sería el que representase una acción por sí misma, sin referencia a ningún otro fin, como objetivamente necesaria. El imperativo dice, pues, qué acción posible por mí, es buena, y representa la regla práctica en relación con una voluntad que no hace una acción sólo por que ésta sea buena y también porque, aun cuando lo 
supiera, pudieran sus máximas ser contrarias a los principios objetivos de una razón práctica. (...) El imperativo hipotético dice solamente que la acción es buena para algún propósito posible o real. (...) El imperativo categórico, que si referencia a propósito alguno, es decir, sin ningún otro afán, declara la acción objetivamente necesaria en sí, tiene el valor de un principio apodíctico práctico (1967:62).

La segunda cuestión que plantea el autor es la responsabilidad de los actos. No sólo debemos hacer las cosas porque son buenas, tenemos el deber de hacerlas y el deber de responsabilizarnos de nuestros actos y palabras. Estas afirmaciones llevan implícita otra cuestión: la libertad del hombre, que es lo que le hace responsable de sus actos. Kant distingue dos mundos: el de la naturaleza y el mundo de la libertad. El primero está determinado por la causalidad natural, pero junto a ella, Kant admite una causalidad por libertad, que rige en la otra esfera. Esta idea, la de la responsabilidad es importante en cuanto que la sociedad de hoy en día tiene un escaso interés por la misma. Es más, la libertad, como dice Kant, es la que nos tiene que llevar a esa responsabilidad y, como sabemos, la idea de libertad que se tiene en la sociedad actual y en la publicidad es bien distinto. Es más bien una libertad que nos permite hacer lo que queramos, sin estudiar las consecuencias y, por supuesto, sin una responsabilidad implícita. Kant también trata la idea de felicidad y lo hace de la siguiente manera:

El poder, la riqueza, la honra, la salud misma y la completa satisfacción y el contento del propio estado, bajo el nombre de felicidad, dan valor, y tras él, a veces, arrogancia, si no existe una buena voluntad que rectifique y acomode a un fin universal el influjo de esta felicidad. (...) En realidad, encontramos que cuanto más se preocupa una razón cultivada del propósito de gozar la vida y alcanzar la felicidad, tanto más el hombre se aleja de la verdadera satisfacción; por lo cual muchos, y precisamente los más experimentados en el uso de la razón, acaban por sentir. Sean lo bastante sinceros para confesarlo- cierto grado de misología u odio a la razón, porque computando todas las ventajas que sacan. No digo ya de la invención de las artes todas del lujo vulgar, sino incluso de las ciencias- que al fin y al cabo aparécenles como un lujo del entendimiento, encuentran, sin embargo, que se han echado encima más penas y dolores que felicidad hayan podido ganar, y más bien envidian que desprecian al hombre vulgar, que está más propicio a la dirección del mero instinto natural y no consiente a su razón que ejerza gran influencia en su hacer y omitir (1967:27).

Como vemos, el autor hace hincapié en la obsesión que existe por alcanzar la felicidad, obsesión que en la mayoría de las ocasiones no sólo no nos hace ser felices, sino más desgraciados. El hombre siempre quiere más y la sociedad, y en este caso la publicidad le muestra unos parámetros de felicidad que en pocas ocasiones se pueden conseguir. Tener el último modelo de coche o la ropa más cara es, según la publicidad, la clave de la felicidad, cuando realmente no es así y no todos tiene el poder económico para adquirir esos productos. Es decir, hoy en día el dinero es que el que hace la felicidad, porque es el que nos permite comprar, comprar la ropa más 
chic que nos permitirá tener más amigos o tener el coche más moderno y estiloso que nos permitirá tener un mejor trabajo, o bien usar los productos que nos hacen eternamente jóvenes para tener una pareja guapa, rica e inteligente. Éste es el enfoque que hace la publicidad de la felicidad, felicidad que vende en sus productos y servicios como si éstos fueran envueltos por su aura mágica, aura que nos lleva inmediatamente a la mejor de las felicidades. Esta idea la hemos recalcado a lo largo de esta investigación y seguiremos hablando de ella. ¿Por qué? Pues porque, al igual que otros filósofos, Kant asegura que la propia felicidad es un deber- al menosindirecto y que ese deber de ser feliz es el que hace que su conducta tenga un verdadero valor moral. Esto es, que todos los autores apuntan la felicidad como un deber del hombre o un fin al que debe llegar. Es cierto, todos la ansiamos, pero quizá no sepamos dónde encontrarla. Por eso nos fiamos de la felicidad que nos promete la publicidad, que parece muy segura de saber dónde está.

\subsection{Nietzsche y su voluntad de poder}

Con Nietzsche vemos un cambio de planteamiento moral. De hecho, el autor defiende la no moral. Como explica Julián Marías es un afirmador de la individualidad poderosa: el bien máximo es la vida misma, que culmina en la voluntad de poder. El hombre debe superarse, terminar en algo que esté por encima de él, como el hombre está por encima del mono; eso es el superhombre (1941:48).

En este análisis de Marías se resumen los puntos fundamentales de la filosofía o planteamiento que hace Nietzsche. En primer lugar habla de la individualidad del hombre. En segundo lugar, la voluntad de poder que debe tener toda persona. Y estas dos ideas nos llevan a la idea fundamental para nosotros de la filosofía del autor: el superhombre.

Este superhombre se caracteriza por los siguientes rasgos:

- Rechaza la moral de los esclavos

- Crea nuevos valores, ajenos a la moralidad y en relación directa con el mundo de la vida.

- No cree en realidades trascendentes ni en Dios

- Le gusta el riesgo, las nuevas experiencias

- Ama la intensidad de la vida, la alegría, el entusiasmo.

- Es dueño de su vida y vive en libertad

Si analizamos estas características nos daremos cuenta de que el superhombre del que habla Nietzsche no es ni mucho menos un personaje negativo, sino que tiene valores como el de la superación, el de la alegría de vivir, el de la lucha. Lo cierto es que ha sido malinterpretado en muchas ocasiones y usado para fines que no le corresponden, siendo su personalidad manipulada según los intereses. Es el caso del nazismo, que utilizó este concepto de superhombre de forma equivocada y como justificación de actos atroces.

Pero además, ese superhombre, fuerte, poderoso, independiente, es el superhombre y supermujer que propugna la publicidad. Todos debemos ser superhombres, es la moral de los fuertes, en contra de los débiles y enfermos. Sólo triunfa el más fuerte, el más guapo, el más listo, el que no cree en nada ni en nadie más que en sí mismo y sus posibilidades. ¿No es cierto que lo débil, enfermizo o fracasado es lo que nunca sale 
en los anuncios y que los protagonistas de los anuncios son fuertes, llenos de vida, con clase y con buena posición social, es decir, poder?

\subsection{Utilitarismo. El placer conduce a la felicidad.}

La siguiente corriente filosófica que vamos a conocer es el utilitarismo. Bajo la denominación de utilitarismo nos encontramos diversas corrientes nacidas a finales del siglo XVIII y desarrolladas a lo largo del siglo XIX en Inglaterra. Las tres figuras más importantes dentro de este movimiento son Jeremy Bentham, James Mill y John Stuart Mill. Uno de los antecedentes de esta corriente lo encontramos en Helvecio, que afirmaba que la vida del hombre giraba en torno a la búsqueda de la felicidad y la voluntad de evitar dolor. Y ese aspecto, el de la búsqueda de la felicidad es en el nosotros nos vamos a centrar dentro del utilitarismo. Según Mill, el fundamento del Utilitarismo o del Principio de Mayor Felicidad mantiene que las acciones son correctas en la medida en que tienden a promover la felicidad e incorrectas en cuanto tienden a producir lo contrario a la felicidad. Pero ¿qué se entiende por felicidad? Sería el "placer o la ausencia de dolor, por lo que la infelicidad sería el dolor y la falta de placer (Robinson-Chris, 2005:71)", los dos amos soberanos del hombre y que determinan su conducta, como añade Dave Robinson. Esta idea era ratificada por Bentham, quien consideraba que el utilitarismo podría suponer un cambio en la sociedad, una reforma que debía basarse en la concepción del dolor y el placer como dos elementos fundamentales en la naturaleza. Para el autor esta máxima felicidad permite distinguir entre lo correcto y lo incorrecto. Derivado de este planteamiento y como consecuencia del mismo, vemos como la premisa básica del utilitarismo es la búsqueda del máximo placer para el mayor número de personas posible, ya que ese placer es la causa directa de la felicidad. Es decir, los utilitaristas creían saber cómo se consigue la felicidad, con el placer y la ausencia de dolor. Otra idea novedosa dentro de esta corriente, es que los utilitaristas consideraban que era posible medir esos placeres, una complicada e imposible labor a nuestro juicio. Pero ¿de qué manera se podía conseguir esto? Pues de la siguiente forma: de acuerdo a su intensidad, duración, certidumbre o incertidumbre, proximidad o alejamiento y el número de gente afectada (2007:71). Como explica Esperanza Guisán, en las teorías de Mill "se demuestra que la felicidad humana es un logro difícil que implica la puesta en marcha de una serie de resortes morales, que en nada se asemejan a la felicidad que pudieran disfrutar nuestros hermanos los cerdos (2007:7)". Pero iban más allá de esta idea, ya que John Stuart Mill consideraba que los placeres no sólo se podían medir de forma cuantitativa sino también de forma cualitativa, ya que apuntaban determinados placeres eran más deseables que otros, como por ejemplo el intelecto. Lo cierto es que, como apunta Esperanza Guisán, esta calidad de los placeres planteada por Mill es una de las diferencias de la doctrina del autor con la planteada por Bentham y que lo han llegado a considerar- a este primero- como un utilitarista semi-idealista (Mill, 2007:52).

En este sentido, y como reflexión a estos postulados utilitaristas, podemos decir que la publicidad comparte estos ideales, ya que, como hemos dicho en ocasiones anteriores, vende la felicidad, a través de productos y servicios, los cuales permiten a 
su vez cuantificarla. Es decir, el que tiene más coches, más dinero, más propiedades, viste con ropa de marca, etc, es más feliz que el que no lleva ese estilo de vida. Cuestión interesante ésta que seguiremos abordando a lo largo de esta investigación. Pero Mill va más allá y afirma que la moral utilitarista reconoce en los seres humanos la capacidad de sacrificar su propio mayor bien por el bien de los demás. Sólo se niega a admitir que el sacrificio sea en sí mismo un bien. Un sacrificio que no incremente o tienda a incrementar la suma total de la felicidad, se considera como inútil. La única auto-renuncia que se aplaude es el amor a la felicidad o a algunos de los medios que conducen a la felicidad de los demás, ya bien de la humanidad colectivamente o de individuos particulares, dentro de los límites que imponen intereses colectivos de la humanidad. Esa moralidad que defiende Mill, guarda relación con la siguiente idea que plantea Dave Robinson, que afirma que "para los utilitaristas, los motivos carecen de importancia, sólo cuentan las consecuencias. El acento recae en el acto más que en el agente (...) De ahí que el utilitarismo se conozca también como consecuencialismo (2005:73)"... En este sentido, Robinson añade que "en su ensayo Sobre la Libertad, Mill mostraba su preocupación por la tiranía de la mayoría. Era un gran pluralista. Una sociedad saludable sería aquella integrada por una enorme variedad de individuos y estilos de vida diferentes (...) A condición de que no se interfiera en las libertades de los demás, debería permitirse que cada uno piense y haga lo que desee (2005:77)". Esta idea anterior que plasma Mill la vuelve a recordar Esperanza Guisán cuando dice que nunca se insistirá suficientemente en que el utilitarismo de Mill no guarda relación alguna con el hedonismo egoísta (...) sino que es más bien un hedonismo universalista, que pone en un mismo plano los intereses personales y los ajenos (Mill, 2007:66). Es más, Mill considera que "la educación y la opinión pública, que tienen un poder tan grande en la formación humana, utilicen de tal modo ese poder que establezca en la mente de todo individuo una asociación indisoluble entre su propia felicidad y el bien del conjunto (2007:67)". Respecto a esta cuestión, recalcamos, al igual que Mill, la importancia de la opinión pública en la formación del hombre y ¿no es cierto que la publicidad crea opinión pública? De ahí la necesidad de reclamarle más responsabilidad y ética en su labor, ya que ésta se convierte en un factor importante dentro de la sociedad. Como reflexión final sobre el utilitarismo y su aplicación práctica hoy en día, podemos decir que en la actualidad, una gran parte de los anuncios que podemos ver en los medios de comunicación se basan en esta teoría, ya que venden la felicidad, es decir, productos que hacen que uno sea más feliz aunque eso no llegue a ser cierto del todo. Ésa es la máxima actual de la publicidad: vender sueños que hagan feliz a la gente y convencerles de que una crema para el cutis puede conseguir que irradien felicidad y se olviden todos los problemas. Y esto lo hacen sin medir los motivos reales, como postulaban los utilitaristas. Sólo se tienen en cuenta las consecuencias, es decir, el objetivo final, vender. Los motivos, que serían los medios, no importan. Da igual engañar a los consumidores prometiéndoles cosas que realmente no se cumplirán. Por llevar ropa de una marca determinada no tendré más amigos, por ejemplo, como se vende en algunos anuncios. Y otra pregunta más, ¿no es cierto que en la sociedad actual sí tenemos una forma de medir los placeres y la felicidad? Quizá sería a través del consumo y de los productos que poseemos. Ésos son los que hacen que seamos más o 
menos felices, o que lo creamos al menos, según nos transmite la publicidad ¿no? Ésta es otra de las ideas que iremos desarrollando a lo largo de este trabajo.

\section{CONCLUSIONES}

El primer movimiento que describe a una parte de la publicidad actual es el sofismo. Lo importante es la retórica: se trata de decir las cosas de modo que convenzan, de decirlas bien. La verdad no importa. Ese desdén por la verdad, al menos absoluta, está reflejada también en los cínicos. Por lo que ya vemos, dos corrientes filosóficas cuyos postulados coinciden, en muchas ocasiones, con lo que se deriva de la práctica publicitaria, idea que iremos desgranando más adelante.

Vamos más allá y al concepto de verdad, añadimos el de felicidad. ¿Qué vende la publicidad de hoy en día si no es placer o felicidad? Todo lo que compramos lleva, de forma inherente, un valor inmaterial, que siempre culmina en la felicidad. Por ejemplo, en un anuncio de una crema para el cutis, quien la muestra es una señora estupenda, que irradia felicidad, juventud y alegría. Pero ¿realmente esa crema tendrá los mismos efectos en nuestro rostro? Cualquiera puede concluir en que no, nunca nos pareceremos a la mujer del anuncio, ni seremos más felices por usar esa crema. Pues bien, los estoicos, los epicureos, Kant o el utilitarismo tienen como ideas centrales de su filosofía la felicidad del hombre, la misma idea central que tiene la publicidad actual: hacernos creer que seremos más felices por usar un determinado producto.

Viendo la teoría de Nietzsche también nos parece estar viendo otro de los principios de la publicidad actual: la voluntad de poder. De esta manera, en cualquier anuncio no sólo se utiliza como reclamo a unos protagonistas de gran belleza física, en la mayoría de las campañas publicitarias, sino que éstos también tienen éxito social, pertenecen a una clase social elevada, es decir, tienen voluntad de poder. La misma voluntad de poder que la publicidad intenta vender al consumidor. Es decir, la crema para el cutis no sólo me hará más feliz, sino que me hará parecer a esa mujer del anuncio, de clase social elevada, con poder, prestigio social y éxito. Si seguimos analizando la teoría de Nietzsche, vemos cómo se puede extrapolar otro de sus puntos clave a la publicidad: lo bueno es lo sano, lo vital, el dominio de poder. Lo malo es lo débil, lo enfermizo y lo fracasado. ¿No es cierto que en la publicidad postulan esos valores buenos según Nietzsche, y se dejan de lado los valores malos? Y otra cuestión ¿no es cierto que la publicidad da entender que esos valores malos podemos convertirlos en buenos usando determinados productos?

De esta forma, observamos como los paradigmas filosóficos de diversas épocas y autores se asemejan a los que rigen la actividad publicitaria. En cualquier caso, esta similitud no viene más que a demostrar, de nuevo, el acierto en el uso del criterio ético a la hora de evaluar la práctica publicitaria.

\section{REFERENCIAS}

\section{Libros Completos:}

Aristóteles (1992): Moral a Nicómano. Madrid: Colección Austral. 
Aristóteles (2000): Metafísica. Madrid: Biblioteca Básica Gredos.

Aristóteles. (2003): Ética Eudemia. Buenos Aires: Losada.

Aznar, H. y Catalán M. (2000): Códigos éticos de publicidad y marketing. Barcelona: Ariel.

Aznar, H. (1999): Comunicación responsable. Barcelona: Ariel.

Bonete, E. (1999): Ética de la comunicación audiovisual. Madrid: Tecnos.

Blackburn, S. (2007): La historia de la República de Platón. Barcelona: Debate.

Jenofonte. (1967): Recuerdos de Sócrates. Madrid: Alianza Editorial.

Kant, I. (1967): Fundamentación de la metafísica de las costumbres. Madrid: Colección Austral.

Long, A. (1984): La filosofía helenística. Madrid: Alianza Universidad.

Marías, J. (1941): Historia de la filosofía. Madrid: Alianza Editorial.

Melero Mellido, A. (1996): Sofistas. Testimonios y fragmentos. Madrid: Gredos.

Mill, J.S. (2007): El utilitarismo. Madrid: Alianza Editorial.

Nietzsche, F. (2005): Así habló Zaratrusta. Madrid: Alianza Editorial.

Platón. (1989): La República. Barcelona: Edit. Ceac.

Platón. (1992): Mitos. Madrid: Ediciones Siruela.

Platón. (2003): Diálogos. Barcelona: Omega.

Ramos Nicolás, S (2008): La venta personal y la dirección de ventas desde un prisma ético.

Murcia: Seneca.

Robinson-Chriss, D. (2005): Ética para todos. Barcelona: Paidós.

Roura, V. (2001): Cultura, ética y prensa. Barcelona: Croma Paidós.

Zubiri, X (2005): El hombre, lo real y lo irreal. Madrid: Alianza Editorial.

\section{Autores}

\section{María Teresa Pellicer Jordá}

Es doctora por la Facultad de Comunicación de la Universidad de Murcia, donde trabaja como profesora de las asignaturas Técnicas de investigación publicitarias, Responsabilidad y Autorregulación Publicitarias y Deontología de la Comunicación Audiovisual. Es licenciada en Periodismo y en Publicidad y Relaciones Públicas. Ha escrito dos libros, titulados 'La publicidad como industria cultural' y 'Ética y estrategias publicitarias', así como numerosos artículos en revistas especializadas. Además, posee una amplia experiencia en el campo de la comunicación, ya que durante varios años estuvo trabajando en reconocidos medios de comunicación de la Región de Murcia.

\section{Antonio Parra Pujante}

Es doctor por la Facultad de Comunicación de la Universidad de Murcia, donde trabaja como profesor. Es una reconocida figura en el periodismo, tanto a nivel regional como nacional, ya que ha trabajado en importantes medios de comunicación. Es autor de numerosos artículos y libros relacionados con los medios de comunicación, como por ejemplo 'De la prensa a los grandes medios de comunicación' o 'Periodismo y verdad'. 